\title{
Analisis Beban Mental Pekerja untuk Perbaikan Sistem Kerja pada Konveksi XYZ dengan Metode NASA-TLX
}

\author{
Gisya Amanda Yudhistira" ${ }^{* 1}$, Melinska Ayu Febrianti², dan \\ Mohammad Arsyad Fathurrohman ${ }^{3}$ \\ 1,2,3 Program Studi Teknik Industri, Fakultas Teknologi Industri, Universitas Islam Indonesia, \\ Jl. Kaliurang KM 14.5, Kab. Sleman, DI Yogyakarta, 55584, Indonesia \\ 18522318@students.uii.ac.id ${ }^{1}, 18522320 @$ students.uii.ac.id², 18522186@ students.uii.ac.id ${ }^{3}$
}

DOI: 10.20961/performa.19.2.46426

\begin{abstract}
Abstrak
Adanya sumber daya manusia bagi perusahaan yang bergerak pada bidang produksi sangatlah penting. Salah satu perusahaan produksi yang terus mengalami peningkatan permintaan adalah Konveksi XYZ Yogyakarta. Banyaknya tuntutan untuk memenuhi permintaan produksi berdampak pada kondisi pekerja, khususnya berkaitan dengan beban mental. Hal ini dapat menyebabkan turunnya produktivitas dalam suatu waktu. Penelitian ini bertujuan untuk memberikan evaluasi terkait beban mental pekerja berdasarkan perhitungan eksperimental dalam percobaan. Dalam penelitian ini dilakukan pengukuran subjektif dengan metode NASA-TLX terhadap penjahit. Terdapat enam indikator yang akan dibandingkan dan diberikan rating. Hasil perhitungan dari penelitian menunjukkan bahwa nilai rata-rata beban kerja mental karyawan sebesar 54.08 dan berada pada kategori tinggi. Kemudian, analisis faktor yang menyebabkan beban mental tinggi menggunakan diagram fishbone dan diperoleh beberapa faktor yang mempengaruhi seperti kurangnya waktu istirahat, tingginya permintaan, jumlah pekerja, maintenance mesin, dan keadaan lingkungan. Hal ini menandakan tingginya beban kerja pada konveksi XYZ lebih tinggi dibandingkan kapasitas para pekerjanya.
\end{abstract}

Kata kunci: beban kerja mental; fishbone; konveks; NASA-TLX; rating

\section{Abstract}

The human resources for companies engaged in production are very important. One of the production companies that continues to experience increased demand is XYZ Convection Yogyakarta. Many demands have an impact on worker conditions, especially with regard to mental workload. This can lead to a decrease in productivity at a time. The study aims to provide an evaluation of workers mental workload based on experimental calculations in experiments. In this study, subjective measurements were made with nasa-TLX method against tailors. There are six indicators to be compared and rated. Calculations from the study showed that the average employee mental workload was 54.08 and was in the high category. Then, analyze the factors that cause high mental load using fishbone diagrams and obtain several affecting factors such as lack of rest time, high demand, number of workers, maintenance of machinery, and environmental circumstances. This indicates that the high workload at XYZ convection is higher than the capacity of its workers.

Keywords: convection; fishbone; mental workload; NASA-TLX; rating

\section{Pendahuluan}

Hasrat manusia untuk memiliki suatu barang atau menggunakan sebuah jasa guna memenuhi kebutuhan jasmani maupun rohani dalam kehidupan sehari-hari diartikan sebagai kebutuhan. Pengertian tersebut membuat kebutuhan manusia menjadi hal mendasar dalam menjalani kehidupan sehari-harinya (Gunawijaya, 2017). Terdapat tiga pengelompokkan kebutuhan manusia berdasarkan tingkat kepentingan. Pengelompokkan yang pertama adalah kebutuhan primer, kemudian dilanjutkan dengan kebutuhan sekunder, dan yang terakhir adalah kebutuhan tersier (Rosari, 2013). Semua kebutuhan tersebut saling berkolaborasi dan saling melengkapi satu sama lain guna menunjang serta dapat memberikan kepuasan pada manusia. Kebutuhan yang

Corresponding Author: 18522318@students.uii.ac.id 
paling penting atau kebutuhan yang harus terpenuhi terlebih dahulu adalah kebutuhan primer, karena kebutuhan primer berhubungan dengan pangan, sandang, dan papan yang membuat 3 hal pokok dalam kebutuhan primer tersebut jelas harus ada sebagai syarat untuk menjalani kehidupan(Syarifuddin, 2016). Oleh karena itu, kebutuhan primer menjadi kebutuhan yang wajib diusahakan pemenuhannya untuk membantu menunjang kehidupan manusia (Nuryadin, 2014).

Kebutuhan sandang menjadi salah satu bagian dari kebutuhan primer yang memberikan manfaat bagi manusia untuk melindungi tubuh dari rasa panas atau dingin. Istilah sandang lebih populer di masyarakat dengan sebutan pakaian. Kebutuhan manusia untuk membeli pakaian mengalami peningkatan setiap tahunnya diiringi dengan berkembangnya model atau fashion yang terjadi begitu cepat (Yakin, 2017). Konveksi menjadi salah satu bisnis rumahan yang memproduksi pakaian jadi guna membantu memenuhi kebutuhan manusia berupa pakaian atau sandang (Arista, 2014). Usaha konveksi menjadi salah satu usaha yang menjanjikan karena memiliki pangsa pasar yang jelas dan menjanjikan. Selain itu ketika seseorang akan membuka usaha konveksi tidak memerlukan modal yang cukup besar (Pratiwi,et al, 2017). Usaha konveksi juga akan membantu dalam membuka lapangan pekerjaan bagi orang-orang pengangguran yang tidak mempunyai keterampilan (Filbert,et al, 2018).

Konveksi XYZ merupakan salah satu usaha konveksi yang berada di Yogyakarta. Konveksi tersebut selalu mendapat jumlah pesanan produksi yang cukup banyak sehingga harus benarbenar memperhatikan kualitas dari pekerjanya untuk dapat membantu meningkatkan produksi yang dilakukan (Indriani, 2016). Pengelola konveksi XYZ harus memastikan kondisi dari para karyawan yang bekerja dalam keadaan baik agar tidak timbul beban kerja yang berlebihan. Ketika beban kerja masuk dalam kategori tinggi akan menimbulkan stres saat bekerja karena ketidakmampuan pekerja atau individu untuk memenuhi tugas atau pekerjaan yang diberikan (Chandra \& Adriansyah, 2017). Selain menyebabkan stres, pekerja yang memiliki beban kerja akan mengganggu performa saat bekerja sehingga akan membuat kualitas pekerja menurun dan hasil produksi yang tidak maksimal (Irawati \& Carollina, 2017).

Melalui penelitian ini akan dilakukan pengukuran beban kerja yang dirasakan karyawan konveksi XYZ saat melakukan pekerjaannya. NASA-TLX menjadi metode yang diambil untuk membantu melakukan pengukuran beban kerja sesuai dengan tuntutan pekerjaan yang diberikan kepada para karyawan (Putri \& Handayani, 2017). NASA-TLX pertama dikemukakan oleh Sandra G, pada tahun 1981 dengan menggunakan kuesioner yang bersifat subjektif dari karyawan atau pekerja digunakan untuk membantu menilai beban kerja yang dirasakan dari sisi pekerja tersebut (Reid \& Nygren, 1988). Metode ini pada awalnya dikembangkan melalui 9 faktor pengukuran beban kerja yang kemudian dipangkas menjadi enam faktor, antara lain Physic Demand (PD), Frustration (FR), Mental Demand (MD), Performance (P), dan yang terakhir adalah Temporal Demand (TD) (Putri \& Handayan, 2017).

\section{Metode Penelitian}

Penelitian yang dilakukan pada salah satu rumah konveksi XYZ yang berada di Sleman, Yogyakarta. Salah satu konveksi yang bergerak pada pembuatan jaket, kaos, baju lapangan dan lain sebagainya. Penelitian ini mengambil subjek sebanyak 8 pekerja pada bidang penjahitan dengan jam kerja 14 jam dan istirahat 3 jam. Rumah Konveksi XYZ ini selalu mendapatkan permintaan dari pelanggan dalam kota maupun luar kota. Dengan banyaknya pesanan pekerja dapat menambah waktu lembur untuk menyelesaikan pekerjaan. Awal penelitian dilakukan dengan melakukan observasi tempat kerja, didapatkan pada bidang penjahitan karena peneliti memilih subjek tersebut agar mendapatkan banyak data. Dimaksudkan bahwa penelitian ini bernilai subjektif oleh pekerja untuk mendapatkan nilai beban mental kerja yang kemudian dapat menjadikan bahan analisis serta pemberian usulan oleh peneliti. Objek penelitian ini yaitu beban mental seorang pekerja yang dihitung melalui metode NASA-TLX. Alur penelitian dapat dilihat pada Gambar 1. 


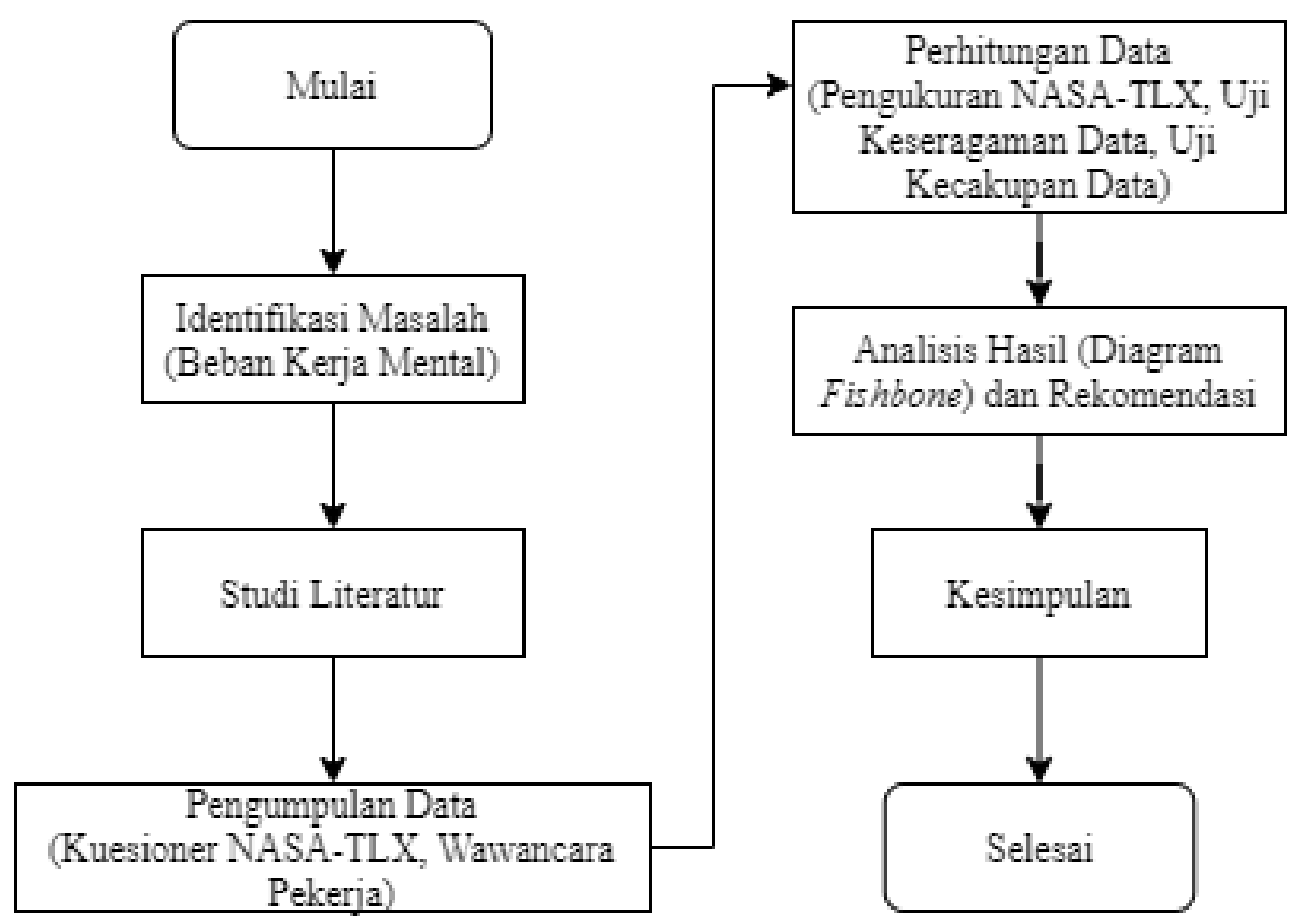

\section{NASA-TLX}

Gambar 1. Alur Penelitian

Adapun perhitungan untuk mendapatkan nilai akhir dari beban kerja mental terhadap 6 dimensi. Perhitungan menggunakan metode NASA-TLX dilakukan dua tahapan. Pertama, pemberian bobot (weights) dan kedua, pemberian peringkat atau sering disebut dengan ratings (Sari, 2017). Pemberian bobot dengan melakukan wawancara terhadap pekerja dengan memilih antara dua indikator yang dirasakan oleh pekerja lebih dominan berdampak pada pekerja yang terdiri dari 15 perbandingan antar dimensi. Kemudian, menurut Sandra G (2006) dalam Amri \& Herizal (2017) pemberian peringkat dengan menilai indikator berdasarkan skala 0-100. Cara perhitungan untuk mendapat nilai rata-rata beban kerja mental, antara lain:

1. Melakukan perbandingan antar indikator dan menjumlahkan nilai dari indikator yang telah dibandingkan dan mendapatkan 6 nilai hasil perbandingan masing-masing indikator.

2. Mengalikan rating dengan jumlah indikator yang telah dibandingkan.

3. Menjumlahkan dari keenam hasil pengalian untuk mencari weighted workload (WWL).

4. Mendapatkan nilai rata-rata WWL dari hasil penjumlahan WWL dibagi dengan 15, yang mana nilai 15 merupakan banyaknya indikator yang dibandingkan. Bentuk rumus dari ratarata WWL dapat dilihat pada persamaan (1).

$$
\text { Rata-rata WWL }=\frac{J u m l a h w w l}{15}
$$

Penjelasan dari Hart dan Staveland (1988) penilaian rata-rata beban kerja mental dikelompokkan menjadi lima kategori. Dapat dilihat pada Tabel 1.

Tabel 1. Klasifikasi Rata-rata

\begin{tabular}{cc}
\hline Kategori & Rata-rata \\
\hline Rendah & $0-9$ \\
Sedang & $10-29$ \\
Cukup Tinggi & $30-49$ \\
Tinggi & $50-79$ \\
Sangat Tinggi & $80-100$ \\
\hline
\end{tabular}




\section{Diagram Fishbone}

Kegunaan pada diagram fishbone yakni menganalisis hal yang menyebabkan permasalahan dapat terjadi. Mengambil kutipan dari Scarvada (2004), fungsi dari penggunaan diagram fishbone yakni untuk mengetahui akar penyebab dari suatu masalah yang digambarkan seperti ikan dari bagian sisi kanan bentuk kepala ikan atau pusat permasalahan yang terjadi. Bagian sisi kiri bentuk duri ikan atau tempat faktor permasalahan mendasar yang terjadi. Kategori penyebab permasalahan yang terjadi berdasarkan analisis dilihat dari beberapa faktor yaitu materials (bahan baku), manpower (tenaga manusia), methods (metode), machines and equipment (mesin dan peralatan), management (manajemen) dan mother naturelenvironment (lingkungan). Sehingga, dikenal dengan istilah $6 \mathrm{M}$.

\section{Hasil dan Pembahasan}

Data diperoleh dari pengisian kuesioner yang dibagikan kepada pekerja dengan pekerjaan yang sama, yakni penjahit. Untuk menguji kecukupan data, maka melakukan uji keseragaman dan kecukupan data sebagai berikut.

\subsection{Uji Keseragaman}

Perhitungan uji keseragaman data dapat dilihat pada persamaan (2), (3), (4), dan (5).

$$
\begin{aligned}
& \overline{\mathrm{x}}=\frac{\sum x_{i}}{n}=\frac{42.66+50+\ldots+57.33}{8}=\frac{432,67}{8}=54.08 \\
& \sigma=\sqrt{\frac{\sum\left(x_{i}-\bar{x}\right)^{2}}{n-1}}=\sqrt{\frac{(42.66-54.08)^{2}+(50-54.08)^{2}+\ldots+(57.33-54.08)^{2}}{8-1}}=\sqrt{\frac{519.5}{7}}=8.61 \\
& \text { BKA }=\overline{\mathrm{x}}+3 \sigma=54.08+3(8.61)=79.91 \\
& \mathrm{BKB}=\overline{\mathrm{x}}-3 \sigma=54.08-3(8.61)=28.25
\end{aligned}
$$

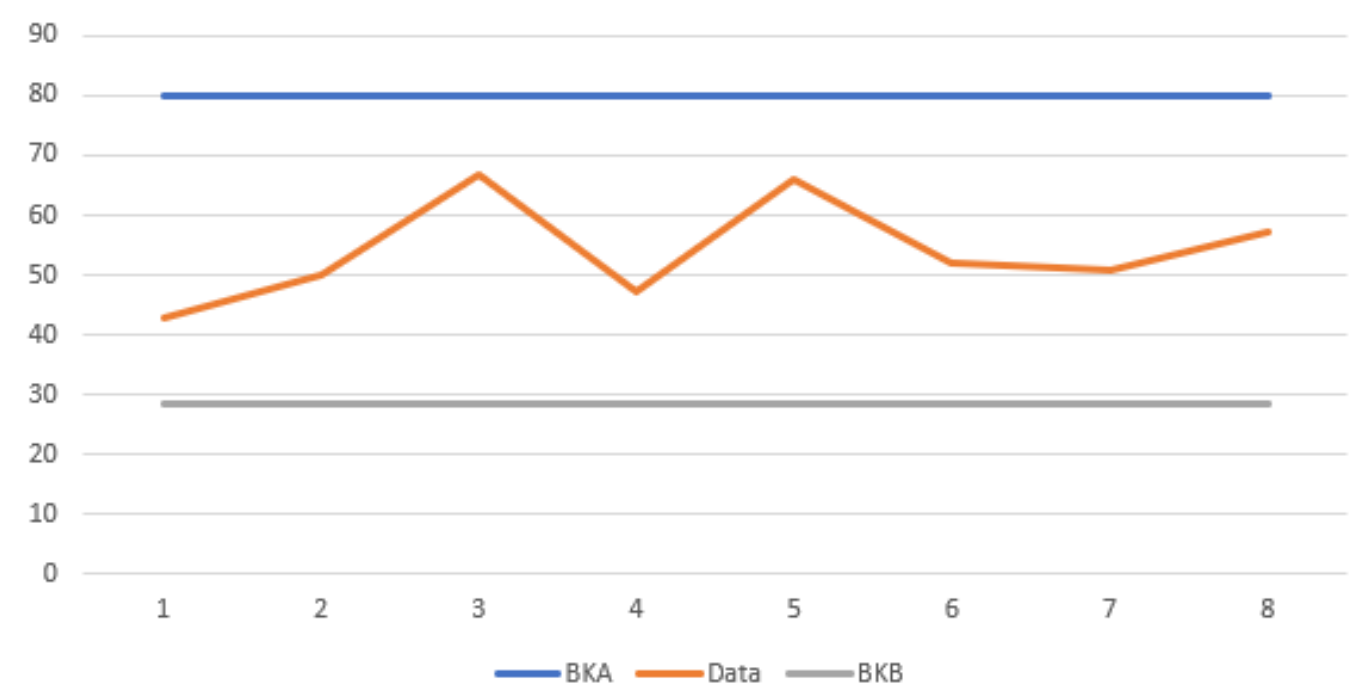

Gambar 2. Grafik Keseragaman Data

Berdasarkan Gambar 1. didapatkan bahwa nilai batas yang didapat adalah BKA sebesar 79.91 dan BKB sebesar 28.25, sedangkan skor NASA-TLX yang didapat paling tinggi sebesar 66.66 dan paling rendah sebesar 42,66. Dengan demikian, skor NASA-TLX yang didapat tidak berada di luar batas dan dapat dikatakan seragam. Sehingga, data tersebut dapat dilakukan ke tahap berikutnya, yakni uji kecukupan data. 


\subsection{Uji Kecukupan Data}

Perhitungan uji kecukupan data dengan tingkat kepercayaan $90 \%(\mathrm{k}=1.65)$ dan derajat ketelitian $10 \%(\mathrm{~s}=0.1)$ dapat dilihat pada persamaan $(6)$.

$$
N^{\prime}=\left(\frac{\frac{k}{s} \sqrt{\left(n \sum\left(x_{i}{ }^{2}\right)-\left(\sum x_{i}\right)^{2}\right)}}{\sum x_{i}}\right)^{2}=\left(\frac{\frac{1.65}{0.1} \sqrt{8(23919.55)-(187200.4)}}{432.66}\right)^{2}=6.044 \approx 6
$$

$\mathrm{N}^{\prime}=6.004$ dan $\mathrm{N}=8$, sehingga nilai $\mathrm{N}^{\prime}<\mathrm{N}$, sehingga dapat dikatakan bahwa data tersebut mencukupi untuk dijadikan bahan penelitian dengan tingkat dari kepercayaan $90 \%$ dan tingkat ketelitian 10\%. Hal ini menandakan bahwa sedikitnya 90 dari 100 nilai rata-rata data memiliki penyimpangan kurang dari $10 \%$.

\subsection{Perhitungan Skor NASA-TLX}

Melakukan perhitungan dengan metode NASA-TLX dengan melakukan wawancara secara langsung kepada pekerja, karena dalam hal ini metode yang digunakan bersifat subjektif. Cara pertama dengan melakukan pembobotan. Hal ini dilakukan dengan cara membandingkan antar indikator untuk setiap pekerja dan didapatkan hasil kumulatifnya untuk setiap indikator MD, PD, TD, OP, EF, FR. Hasil pembobotan dapat dilihat pada Tabel 2.

\begin{tabular}{ccccccc}
\multicolumn{7}{c}{ Tabel 2. Hasil Pembobotan } \\
\hline Nama & MD & PD & TD & OP & EF & FR \\
\hline Pekerja1 & 1 & 3 & 4 & 4 & 3 & 0 \\
Pekerja2 & 3 & 2 & 3 & 2 & 5 & 0 \\
Pekerja3 & 3 & 0 & 4 & 3 & 3 & 2 \\
Pekerja4 & 1 & 2 & 4 & 4 & 2 & 2 \\
Pekerja5 & 2 & 1 & 1 & 3 & 4 & 4 \\
Pekerja6 & 1 & 4 & 3 & 4 & 3 & 0 \\
Pekerja7 & 2 & 2 & 3 & 4 & 4 & 0 \\
Pekerja8 & 1 & 3 & 2 & 5 & 4 & 0 \\
\hline
\end{tabular}

Langkah selanjutnya setelah melakukan pembobotan yaitu memberikan rating. Hal ini dilakukan dengan menanyakan secara subjektif kepada pekerja pada setiap indikator NASA-TLX. Hasil rating dapat dilihat pada Tabel 3.

\begin{tabular}{ccccccc}
\multicolumn{7}{c}{ Tabel 3. Hasil Rating } \\
\hline Nama & MD & PD & TD & OP & EF & FR \\
\hline Pekerja1 & 20 & 50 & 50 & 10 & 50 & 0 \\
Pekerja2 & 100 & 100 & 50 & 50 & 0 & 50 \\
Pekerja3 & 100 & 20 & 80 & 20 & 80 & 40 \\
Pekerja4 & 50 & 60 & 70 & 0 & 70 & 60 \\
Pekerja5 & 100 & 50 & 100 & 0 & 100 & 60 \\
Pekerja6 & 20 & 80 & 40 & 20 & 80 & 20 \\
Pekerja7 & 70 & 50 & 40 & 20 & 80 & 30 \\
Pekerja8 & 50 & 60 & 80 & 30 & 80 & 50
\end{tabular}


Langkah selanjutnya yaitu menghitung nilai produk. Berdasarkan hasil kuesioner yang telah diisi, didapatkan nilai produk dengan perkalian antara rating dan bobot setiap faktornya. Melakukan perhitungan WWL (weighted workload) dengan menjumlahkan hasil nilai produk masing-masing pekerja. Skor akhir didapatkan dari mencari rata-rata WWL, yakni nilai WWL dibagi 15 yang didapat dari kombinasi keenam pasangan aspek beban mental. Perhitungan skor NASA-TLX dari pekerja 1 dapat dilihat pada persamaan (7), (8), (9), (10), (11), (12), (13), dan (14).

$$
\begin{aligned}
& \mathrm{MD}=\text { rating } \mathrm{x} \text { bobot }=20 \times 1=20 \\
& \mathrm{PD} \quad=\text { rating } \mathrm{x} \text { bobot }=80 \times 4=320 \\
& \mathrm{TD} \quad=\text { rating } \mathrm{x} \text { bobot }=40 \times 3=120 \\
& \mathrm{OP} \quad=\text { rating } \mathrm{x} \text { bobot }=20 \times 4=80 \\
& \mathrm{EF} \quad=\text { rating } \mathrm{x} \text { bobot }=80 \times 3=240 \\
& \mathrm{FR} \quad=\text { rating } \mathrm{x} \text { bobot }=20 \times 0=0 \\
& \mathrm{WWL}=\mathrm{MD}+\mathrm{PD}+\mathrm{TD}+\mathrm{OP}+\mathrm{FR}+\mathrm{EF} \quad=20+320+120+80+240+0=780 \\
& \text { Skor } \quad=\frac{\sum w w l}{15}=\frac{780}{15}=52
\end{aligned}
$$

\begin{tabular}{|c|c|c|c|c|c|c|c|c|c|c|c|}
\hline \multirow[t]{2}{*}{ Nama } & \multirow{2}{*}{$\begin{array}{l}\text { Umur } \\
\text { (Tahun) }\end{array}$} & \multirow{2}{*}{$\begin{array}{c}\text { Jenis } \\
\text { Kelamin }\end{array}$} & \multicolumn{6}{|c|}{ Nilai Produk } & \multirow[t]{2}{*}{ Jumlah } & \multirow{2}{*}{$\begin{array}{c}\text { Rata-Rata } \\
\text { WWL = } \\
\text { Jumlah/15 }\end{array}$} & \multirow[t]{2}{*}{ Kategori } \\
\hline & & & MD & PD & TD & OP & $\mathrm{EF}$ & FR & & & \\
\hline Pekerja 1 & 25 & Laki-laki & 20 & 320 & 120 & 80 & 240 & 0 & 780 & 52 & $\begin{array}{l}\text { Cukup } \\
\text { Tinggi }\end{array}$ \\
\hline Pekerja 2 & 29 & Laki-laki & 300 & 200 & 150 & 100 & 0 & 0 & 750 & 50 & Tinggi \\
\hline Pekerja 3 & 29 & Laki-laki & 300 & 0 & 320 & 60 & 240 & 80 & 1000 & 66.66666667 & Tinggi \\
\hline Pekerja 4 & 31 & Laki-laki & 50 & 120 & 280 & 0 & 140 & 120 & 710 & 47.33333333 & $\begin{array}{l}\text { Cukup } \\
\text { Tinggi }\end{array}$ \\
\hline Pekerja 5 & 30 & Laki-laki & 200 & 50 & 100 & 0 & 400 & 240 & 990 & 66 & Tinggi \\
\hline Pekerja 6 & 28 & Laki-laki & 100 & 150 & 200 & 40 & 150 & 0 & 640 & 42.66666667 & Tinggi \\
\hline Pekerja 7 & 25 & Laki-laki & 140 & 100 & 120 & 80 & 320 & 0 & 760 & 50.66666667 & Tinggi \\
\hline Pekerja 8 & 25 & Laki-laki & $\begin{array}{l}50 \\
\text { Rata }\end{array}$ & $\begin{array}{l}180 \\
\text { rata }\end{array}$ & 160 & 150 & 320 & 0 & 860 & $\begin{array}{l}57.33333333 \\
54.08333333\end{array}$ & $\begin{array}{l}\text { Tinggi } \\
\text { Tinggi }\end{array}$ \\
\hline
\end{tabular}

Rekapitulasi data nilai produk dari perhitungan rating dikali dengan bobot setiap faktor beserta klasifikasinya terdapat pada Tabel 4.

Tabel 4. Klasifikasi Skor NASA-TLX

\subsection{Analisis Skor NASA-TLX}

Setelah dilakukan perhitungan beserta klasifikasi beban kerja mental berdasarkan skor NASA-TLX didapatkan hasil beban kerja mental penjahit di Konveksi XYZ tergolong tinggi. Tingginya beban kerja mental pada hal ini dipengaruhi oleh kondisi stasiun kerja yang berbeda antar satu pekerja dengan lainnya, tingkat ketelitian yang dibutuhkan untuk menjahit tinggi, serta tuntutan waktu yang disediakan oleh perusahaan untuk menyelesaikan suatu pekerjaan atau target. Banyaknya permintaan dengan produksi yang besar dapat membuat beban kerja mental pekerja 
semakin tinggi dikarenakan tuntutan waktu yang besar pula. Analisis sebab akibat dari skor beban kerja mental yang tinggi disajikan dengan diagram fishbone yang terdapat pada Gambar 3.

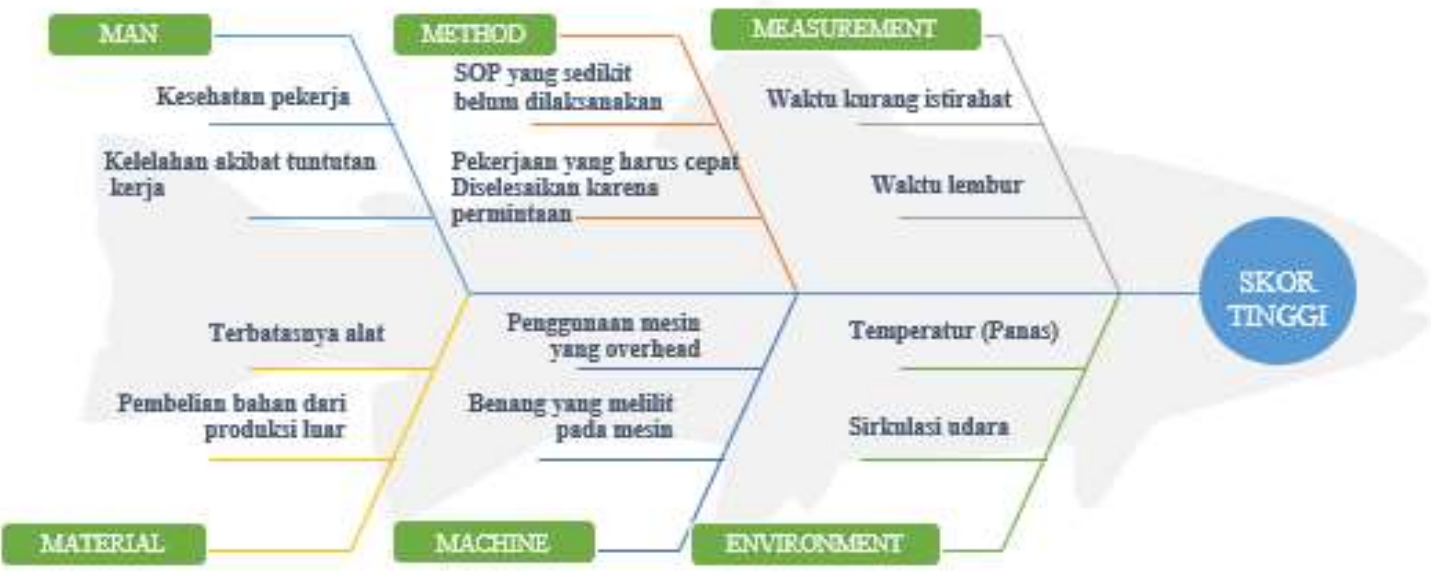

Gambar 3. Diagram Fishbone Faktor Tingginya Beban Kerja Mental

Penjelasan terkait diagram fishbone untuk faktor yang pertama adalah Man yang terdiri dari kesehatan pekerja dan kelelahan akibat tuntutan kerja. Hal ini sangat berpengaruh untuk menunjang produktivitas pekerja. Jika pekerja merasakan badan yang kurang sehat akan berpengaruh kepada performansi untuk dapat melakukan pekerjaannya sampai kapasitas maksimum yang dimilikinya, dimana pekerja ketika melakukan aktivitasnya tidak termotivasi. Sehingga hal itu membuat pekerja tidak dalam kondisi yang prima/baik untuk mengerjakan jobdesc-nya. Selain itu, tuntutan kerja yang tinggi tentunya juga akan membuat pekerja merasa kelelahan. Kelelahan itu juga akan mengakibatkan proses produksi menghambat karena pekerja tidak dapat bekerja secara untuk memenuhi permintaan pelanggan atau konsumen.

Faktor kedua pada diagram fishbone adalah Method yang mengacu pada SOP yang belum dilaksanakan oleh beberapa pekerja dan pekerjaan yang harus cepat diselesaikan karena permintaan dari konsumen. SOP yang tidak dilaksanakan secara keseluruhan dapat berakibat beberapa pekerjaan tidak terlaksana dengan baik sehingga dapat menyebabkan hasil produksi tidak maksimal. Pekerjaan yang tidak maksimal tentunya membutuhkan pemeriksaan ulang yang menyebabkan tambahan jam kerja. Selain membahas tentang SOP, pada aspek Method juga mengacu pada beban pekerjaan yang harus diselesaikan dengan cepat karena permintaan dari konsumen.

Analisis faktor yang ketiga yaitu Measurement yang berhubungan dengan waktu istirahat yang kurang dan adanya waktu lembur. Waktu istirahat yang kurang tentunya membuat pekerja tidak bisa mengembalikan performansi dan tubuh dalam keadaan baik seperti semula. Waktu istirahat yang kurang dan ditambah dengan adanya waktu lembur tentunya akan menjadi beban kerja yang berlebihan. Ketika pekerja sudah mencapai batas kemampuan mereka tentunya hal tersebut akan berpengaruh terhadap hasil produksi dan membuat ketidakmampuan pekerja.

Faktor ketiga berhubungan dengan Material yang membahas tentang terbatasnya alat dan pembelian bahan baku produksi dari luar. Terbatasnya alat membuat pekerja harus memberikan effort yang lebih karena beberapa pekerjaan harus dilakukan secara manual. Pekerjaan yang dilakukan secara manual dan ditambah dengan banyaknya orderan atau permintaan dari konsumen tentunya akan memberatkan atau memberikan beban terhadap pekerja.

Machine merupakan faktor keempat pada diagram fishbone yang mengacu pada penggunaan mesin yang overhead dan benang yang melilit pada mesin.hal ini dapat membuat waktu pekerja menjadi lama karena diharuskan pekerja memperbaiki sistem dari mesin yang digunakan dan apabila menimbulkan kerusakan pada mesin hasil kualitas pada produk pun akan terkena dampaknya. Ketidaksesuaian espektasi hasil produk dengan pekerjaan yang berkaitan dengan kualitas produk dikarenakan faktor dari mesin yang digunakan oleh pekerja. 
Faktor terakhir dalam analisis sebab akibat menggunakan diagram fishbone adalah aspek Environment. Pada aspek Environment membahas tentang temperatur lingkungan kerja yang panas dan sirkulasi udara yang kurang memadahi. Temperatur pada lingkungan kerja tentunya harus selalu diperhatikan supaya dapat memberikan kenyamanan pada pekerja ketika melakukan aktivitas. Keadaan lingkungan yang panas dan tanpa adanya sirkulasi udara yang cukup akan mempengaruhi kondisi fisik. Kondisi fisik yang menurun tentunya akan berakibat menurunkan performansi pekerja.

\subsection{Rekomendasi}

Rekomendasi yang dapat diberikan berupa administrative control dengan diadakannya rotasi kerja serta pembagian shift yang baik sehingga pekerja memiliki waktu istirahat yang cukup guna mencapai tingkat produktivitas yang diinginkan. Hal ini menata ulang waktu istirahat sangat penting yang disesuaikan dengan kemampuan atau batas wajar jam kerja produktif dari seorang pekerja. Jika tidak memiliki kebiasaan dengan jam kerja akan menimbulkan pola rutinitas kerja yang sedikit terganggu diakibatkan karena jam yang tidak teratur, seperti halnya ketika jam kerja operasional dan jam istirahat sudah ditetapkan namun jika terdapat waktu lebur harus disesuaikan lagi dengan kebutuhan waktu istirahat pekerja. Selain itu pekerja dapat memanfaatkan keterampilan dan fasilitas kerja sehingga usaha yang dikeluarkan dapat diminimalisir. Hal ini ketika pekerja memiliki keterampilan yang dimiliki atau hal yang disukai dalam penjalanan aktivitas kerjanya akan semakin terdukung dalam mencapai sebuah hasil dari aktivitas kerja tersebut. Menjadikan beban kerja menjadi sedikit turun. Pembagian tugas sesuai dengan keterampilan yang dimiliki agar usaha untuk mencapai tingkat performansi yang tinggi tidak terlalu besar, dan re-design stasiun kerja sehingga memiliki lingkungan kerja yang nyaman. Redesign lingkungan kerja dapat dilakukan dengan penataan ulang tempat yang tidak berdempetan sehingga terdapat sedikit tambahan pencahayaan dan sirkulasi udara. Penataan yang lebih diperhatikan lagi untuk setiap jarak dari work station tempat menjahit dan juga lingkungan kerja fisik yang perlu diatur dan ditata kembali.

\section{Simpulan}

Beban mental pekerja merupakan selisih antara tuntutan pekerjaan dengan kapasitas maksimal beban mental seseorang saat keadaan termotivasi (Putro, 2018). Hasil dari pengukuran yang telah dihitung berdasarkan metode NASA-TLX dengan perhitungan enam indikator yaitu MD, TD, PD, EF, OP, dan FR, kemudian diberi rating sesuai tingkatannya, menghitung nilai produk, kemudian didapat WWL. Dari hasil pengukuran diperoleh bahwa nilai rata-rata beban kerja mental pekerja sebesar 54.08 dan berada pada kategori tinggi.

Tingginya skor beban kerja mental dapat diidentifikasi menggunakan diagram fishbone berdasarkan enam faktor, yakni materials, manpower, machine and equipment, methods, management dan mother nature/environment. Rekomendasi yang dapat diberikan berupa administrative control dengan diadakannya rotasi kerja dengan pembagian shift yang baik sehingga pekerja memiliki waktu istirahat yang cukup guna mencapai tingkat produktivitas yang diinginkan, selain itu pekerja dapat memanfaatkan keterampilan dan fasilitas kerja, pembagian tugas sesuai dengan keterampilan yang dimiliki dan re-design stasiun kerja.

\section{Ucapan Terima Kasih}

Terimakasih kepada pihak reviewer yang telah bersedia dalam menelaah penelitian yang kami buat. Tak lupa kami ucapkan terimakasih kepada Universitas Islam Indonesia dan Laboratorium Desain Sistem Kerja dan Ergonomi UII yang telah membantu dalam penelitian ini. 


\section{Daftar Pustaka}

Amri, \& Herizal. (2017). Analisis Beban Kerja Psikologis dengan Menggunakan Metode NASATLX pada Operator Departemen Fiber Line di PT . Toba Pulp Lestari, Vol. 6, No. 1, pp. 29-35.

Arista, G. R. (2014). Analisis Usaha-Usaha Penjualan Produk Konveksi (Kasus Pedagang Pasar Plaza Sukarama di Pekanbaru).

Chandra, R., \& Adriansyah, D. (2017). Pengaruh Beban Kerja dan Stres Kerja terhadap Kinerja Karyawan pada PT . Mega Auto Central Finance Cabang di Langsa. Jurnal Manajemen Dan Keuangan, Vol. 6, No. 1, pp. 670-678.

Filbert, E., Zaman, A. N., Prabowo, A. R., Nabila, F., \& Chalifah, R. D. (2018). Kajian Strategi Pengembangan Usaha Pada Industri Konveksi "Scout Shop" di Cibubur. Seminar dan Konferensi Nasional IDEC.

Gunawijaya, R. (2017). Kebutuhan Manusia dalam Pandangan Ekonomi Kapitalis dan Ekonomi Islam, Vol. 13, No. 1, pp. 131-150.

Hart, S. G., \& Staveland, L. E. (1988). Development of NASA-TLX (Task Load Index): Results of empirical and theoretical research. In Advances in psychology (Vol. 52, pp. 139-183). North-Holland.

Indriani, M. (2016). Peran Tenaga Kerja Indonesia dalam Pembangunan Ekonomi Gema Nasional, pp. 1-12.

Irawati, R., \& Carollina, D. A. (2017). Analisis Pengaruh Beban Kerja terhadap Kinerja Karyawan Operator pada PT Giken Precision Indonesia. Jurnal Inovasi dan Bisnis, Vol. 5, No. 1, pp. 53-58.

Nuryadin, M. B. (2014). Pentingnya Pendidikan Ekonomi untuk Terwujudnya Pengelolaan Keuangan Rumah Tangga yang Baik. Vol. 2, No. 2, pp. 1-9.

Pratiwi, A., Santoso, E., \& Fatmawati. (2017). Eskalasi Usaha Konveksi Kaos dan Seragam Kerja Melalui Strategi Kualitas Produk, Pemasaran Melalui E-Commerce pada Wirausaha Forum Difabel Malang Raya, Vol. 4, No. 1, pp. 45-50.

Putri, U. L., \& Handayani, N. U. (2017). Analisis Beban Kerja Mental Dengan Metode NASA TLX Pada Departemen Logistik PT ABC, pp. 1-10.

Putro, W. W., \& Sari, S. I. K. (2018). Ergonomi untuk Pemula:(Prinsip Dasar \& Aplikasinya). Universitas Brawijaya Press.

Reid, G. B., \& Nygren, T. E. (1988). Human Mental Workload. Advances in Psychology, Vol. 52, pp. $185-218$.

Rosari, E. (2013). Konsumtivisme Wanita Dewasa Awal pada Tiga Wilayah Konsumsi: Primer , Sekunder, dan Tersier.

Sandra G. Hart. (2006), Nasa-Task Load Index (Nasa-Tlx); 20 Years Later. NASA-Ames Research Center. Moffett Field, CA

Sari, P. (2017). Pengukuran Beban Kerja Karyawan Menggunakan Metode Nasa-Tlx Di Pt . Tranka Kabel, Vol. 9, No. 3, pp. 223-231.

Scarvada, A.J., Tatiana, B.C., Susan, M.G., dan Julie, M.H., dan Arthur, V.H. (2004). A Review of the Causal Mapping Practice and Research Literature. Second World Conference on POM and 15th Annual POM Conference (Mexico, Cancun, 30 April - 3 Mei 2004). 
Syarifuddin, M. (2016). Analisis Tentang Aktivitas Buruh Tani dalam Memenuhi Kebutuhan Pokok di Kelurahan Bukuan Kecamatan Palaran Kota Samarinda, Vol. 4, No. 3, pp. 98112.

Yakin, M. F. A. (2017). Perilaku Konsumen Dalam Berbelanja Pakaian Wanita di Pasar Pagi Samarinda. 